\title{
Superplasticity in a fine-grained tin alloy processed by multi-directional forging
}

\author{
F. Akbaripanah ${ }^{1}$, Y. Moradi ${ }^{1}$, R.Mahmudi ${ }^{2 \dagger}$ \\ †mahmudi@ut.ac.ir
}

\begin{abstract}
${ }^{1}$ Department of Mechanical Engineering, Faculty of Engineering, Malayer University, Malayer, Iran ${ }^{2}$ School of Metallurgical and Materials Engineering, College of Engineering, University of Tehran, Tehran, Iran
\end{abstract}

\begin{abstract}
Superplastic deformation of engineering materials is often represented by high elongation values obtained in conventional tensile tests carried out in specific ranges of temperatures and strain rates. This behavior is characterized by high strain rate sensitivity (SRS) indices obtained by a variety of techniques. The SRS of a fine-grained $\mathrm{Sn}-1 \mathrm{wt} \% \mathrm{Bi}$ alloy, processed by multi-directional forging $(\mathrm{MDF})$ was studied by indentation testing at room temperature $\left(\mathrm{T}>0.6 \mathrm{~T}_{m}\right)$. The microstructural homogeneity increased with increasing the number of MDF passes, and the grain size decreased from 3.2 to $2 \mu \mathrm{m}$, as the number of passes increased from 1 to 8 . The SRS indices of $0.08,0.24,0.31$, and 0.49 were obtained for the $2,4,6$ and 8 passes of MDF, respectively. The high SRS index of 0.49 , calculated from different analysis methods of the indentation tests are in good agreement with each other and with those of the other testing methods and severe plastic deformation processes on the same alloy reported in the literature. These SRS indices together with the uniform fine-grained equiaxed microstructure with an average grain size of 2 $\mu \mathrm{m}$, observed after $8 \mathrm{MDF}$ passes, are indicative of a superplastic deformation behavior dominated by grain boundary sliding.
\end{abstract}

Keywords: multi-directional forging, strain rate sensitivity, superplasticity

\section{Сверхпластичность мелкозернистого сплава олова, подвергнутого всесторонней ковке}

\begin{abstract}
Сверхпластическая деформация конструкционных материалов часто характеризуется высокими значениями удлинения, получаемыми в обычных испытаниях на растяжение, проводимых в определенных интервалах температуры и скорости деформации. Это поведение характеризуется высокими значениями показателя чувствительности к скорости деформации (ЧСД), которые определяются различными методами. Путем испытаний на твердость при комнатной температуре ( $>0.6 \mathrm{~T}_{\mathrm{m}}$ ) была исследована ЧСВ мелкозернистого сплава $\mathrm{Sn}-1$ вес. \% Bi, подвергнутого всесторонней ковке (ВК). Однородность микроструктуры возрастает с увеличением числа переходов ВК, а размер зерен уменьшается с 3.2 до 2 мкм, когда число переходов увеличивается от 1 до 8. Получены показатели ЧСД $0.08,0.24,0.31$ и 0.49 для 2, 4, 6 и 8 переходов ВК, соответственно. Высокие показатели ЧСД около 0.49, рассчитанные с применением различных методов анализа испытаний на микротвердость, находятся в хорошем согласии друг с другом и со значениями, полученными другими методами испытаний и для других процессов интенсивной пластической деформации, имеющимися в литературе. Эти показатели ЧСД, вкупе с однородной мелкозернистой равноосной микроструктурой со средним размером зерен 2 мкм, наблюдаемой после 8 переходов ВК, свидетельствует о сверхпластическом характере деформации, доминирующим механизмом которой является зернограничное проскальзывание.
\end{abstract}

Ключевые слова: всесторонняя ковка, параметр скоростной чувствительности, сверхпластичность

\section{Introduction}

Severe plastic deformation (SPD) processes have received great attention for their capability in producing very fine grain sizes. Different processes have been developed and their potentials and limitations have been documented. Among these, multi-directional forging (MDF) has proved to be a possible means for attaining fine grain structures suitable for superplastic deformation of aluminum [1], magnesium [2], and titanium alloys [3]. In principle, MDF is a repeating compression process in which the axis of the applied strain changes in each step [4]. Considerable plastic strain is accumulated in the material as it is repeatedly deformed at ambient to elevated temperatures. It has been shown that the evolution of equiaxed fine grains relies mainly on the strain accumulation applied from various directions [5]. 
Most of the studies on the superplastic deformation of severely deformed materials have employed the conventional tensile methods. Localized tests such as indentation creep test, however, can be very useful in this respect. This is because they can be particularly advantageous when the material is only available as small test-pieces or there are some difficulties with the machining of samples made of very soft materials [6]. The indentation creep process can be defined as the time dependent penetration of a hard indenter into the material under constant load and temperature [7]. The variation in penetration depth, expressed as a change in diagonal length, is monitored with dwell time. Accordingly, the stress exponents and strain rate sensitivity (SRS) indices of materials can be determined by these simple hardness tests. The superplasticity of the rolled $\mathrm{Sn}-\mathrm{Pb}$ eutectic [8], Sn- $40 \% \mathrm{~Pb}-2.5 \% \mathrm{Sb}$ peritectic $[9,10]$, and $\mathrm{Sn}-1 \% \mathrm{Bi}$ alloy [11] has been investigated by indentation creep test. In all of these studies, it has shown that the parameters which are commonly considered as characteristics of superplasticity can be obtained by this simple test. One of these parameters is the SRS index $(m)$, which can be used to assess the superplastic behavior.

It is the aim of this study to investigate the superplastic behavior of the fine-grained Sn-l\%Bi alloy processed by MDF at room temperature $\left(\mathrm{T}>0.6 \mathrm{~T}_{\mathrm{m}}\right)$. This was achieved through indentation creep test by measuring the stress exponents and SRS indices, using different methods of analysis.

\section{Experimental Procedure}

\subsection{Materials and processing}

The material used was a $\mathrm{Sn}-1 \mathrm{wt} \%$ Bi alloy. It was prepared from high purity (99.9\%) tin and bismuth, melted in an electrical furnace under an inert argon atmosphere, and cast into $110 \times 13 \times 13 \mathrm{~mm}$ slabs. The slabs for MDF were cut into billets with dimensions of $20 \times 13 \times 13 \mathrm{~mm}$. In order to ensure that the billets had similar initial microstructures, they were homogenized at $425 \mathrm{~K}$ for $8 \mathrm{~h}$. The samples were multi-directionality forged at room temperature at a pressing speed of $2 \mathrm{~mm} \mathrm{~min}{ }^{-1}$. A $0.05-\mathrm{mm}$ thick PTFE film was wrapped around the samples as a lubricant during MDF. As shown in Fig. 1, the loading direction was changed by $90^{\circ}$ sequentially along the three axes of the sample from pass to pass, in such a way that the dimension ratio of 2:1.3:1.3 of the billets was kept unchanged during MDF. The axial pass strain of $\Delta \varepsilon=0.43$ was employed, which is defined as $\Delta \varepsilon=\ln \left|h_{\mathrm{o}} / h_{\mathrm{f}}\right|$, where $h_{\mathrm{o}}$ and $h_{\mathrm{f}}$ are the respective initial and final heights of the billets, resulting in an equivalent strain of $\varepsilon=(2 / \sqrt{3}) \ln \left|h_{\mathrm{o}} / h_{\mathrm{f}}\right| \approx 0.5$ [12]. MDF was carried out up to a maximum cumulative strain of $\Sigma \Delta \varepsilon=3.44$, i.e., a total of eight passes.

The specimens were examined by optical microscopy to determine the grain size and distribution of the forged material. After mechanical polishing, samples were etched using a solution of $60 \mathrm{ml}$ alcohol, $30 \mathrm{ml} \mathrm{H}_{2} \mathrm{O}, 5 \mathrm{ml} \mathrm{HCl}$ and $2 \mathrm{~g}$ $\mathrm{FeCl}_{3}$. The grain sizes and distributions were calculated using the Clemex professional image analysis program according to the ASTM E112 standard.

\subsection{Indentation creep tests}

The samples were polished and then tested in a Vickers hardness tester where the testing time was the only variable. The Vickers indenter was mounted in a holder that was positioned in the center of the vertical loading bar. The specimen was placed in an anvil below the loading bar. The Vickers hardness number is given by $H_{\mathrm{v}}=0.1854 \mathrm{~F} / \mathrm{d}^{2}$, where $F$ is the applied load in $N$ and $d$ is the average diagonal length in $\mathrm{mm}$. Indentation creep measurements were made on each sample using $10 \mathrm{~N}$ load for dwell times up to $120 \mathrm{~min}$. After each loading schedule, the sample was unloaded and the indentation diagonal was measured under a traveling microscope. Each reading was an average of at least three separate measurements taken at random places on the surface of the samples.

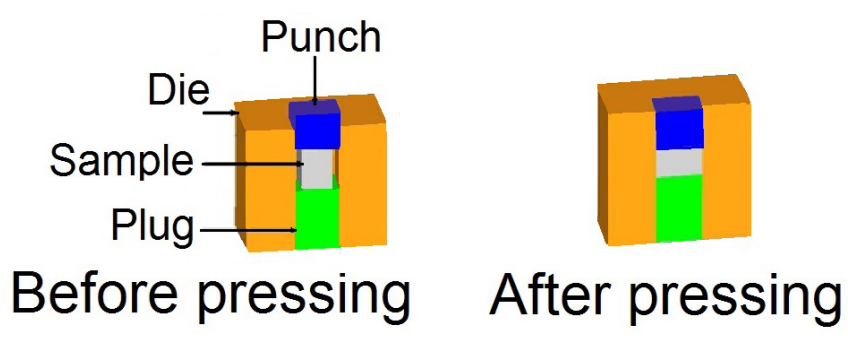

Pressing direction

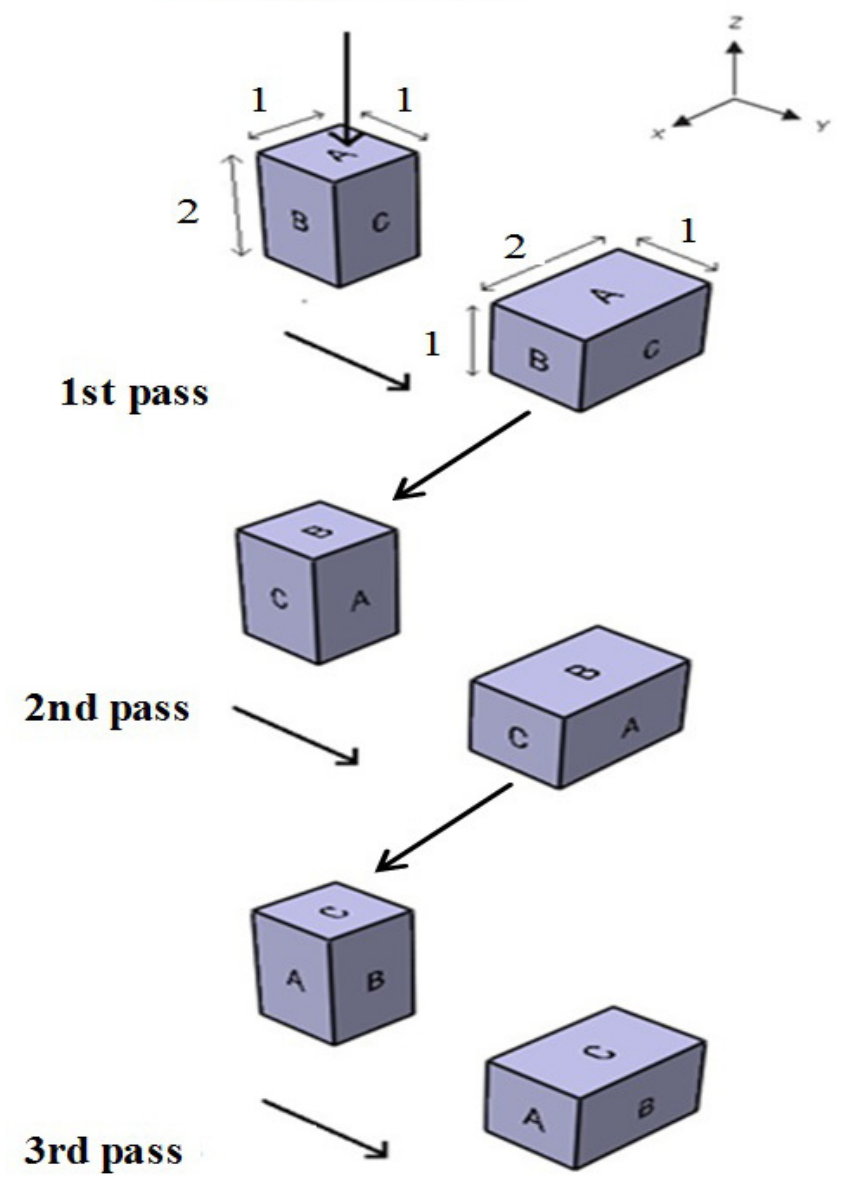

Fig. 1. Schematic illustration of multi-directional forging. 


\section{Results and discussion}

The Optical micrographs of the material before the MDF process and after 8 passes of MDF are shown in Figs. 2 and 3, respectively. As can be observed in Fig. 2a, the unMDFed microstructure consist of some large grains together with many smaller grains which are believed to be formed as result of high cooling rates imparted by the cold mold and the possible static recrystallization at room temperature. The corresponding grain size distribution data, collected from a number of samples, are shown in Fig. 2b. It is clear that a somewhat skewed distribution with an average grain size of about $4.2 \mu \mathrm{m}$ and a standard deviation of $1.9 \mu \mathrm{m}$ has been achieved. However, the microstructure of the material after 8 passes of MDF, depicted in Fig 3a, is indicative of a more refined state, implying that dynamic recrystallization has occurred during the MDF process. The grain size data histogram in Fig. 3b exhibits a normal distribution with an average grain size of about $2 \mu \mathrm{m}$ and a small standard deviation of $0.6 \mu \mathrm{m}$. In fine-grained materials, a uniform grain size distribution is important in achieving homogeneous mechanical properties.

The results of indentation tests are shown in Fig. 4, where the indentation length is plotted against time. It can be inferred from this figure that the indentation diagonal
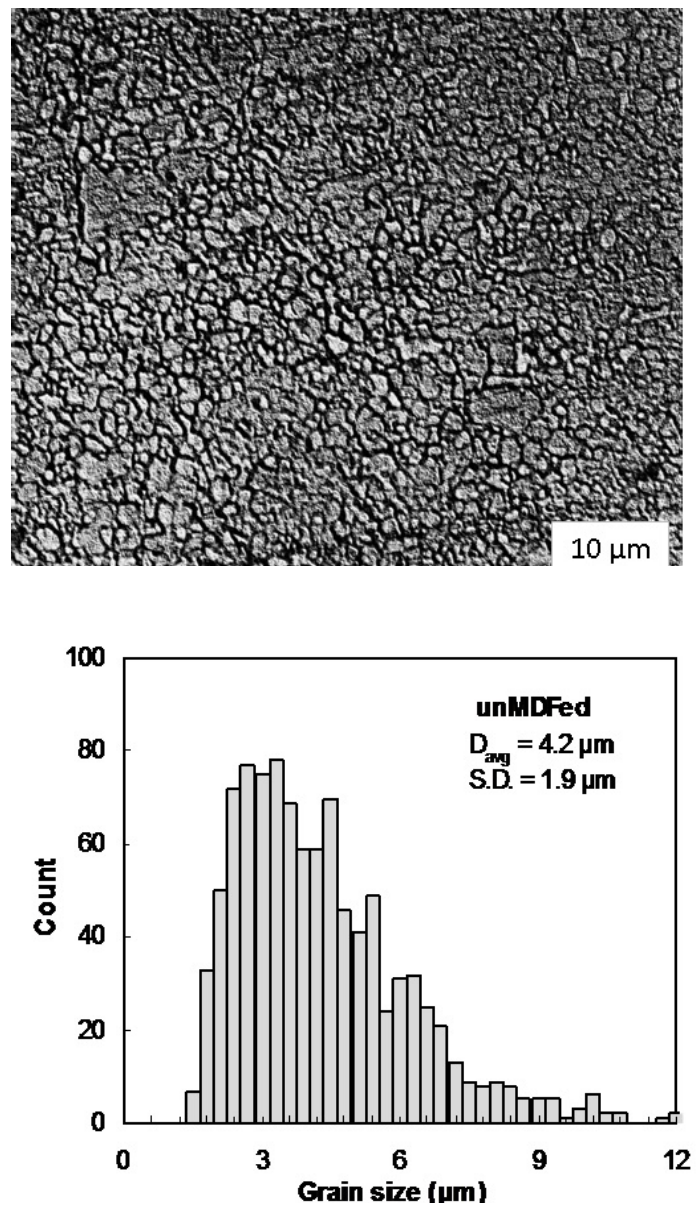

Fig. 2. (a) Optical micrograph and (b) grain size distribution of the unMDFed material. length increases with the loading time and the number of MDF passes. In other words, the level of indentation curves and their slopes in the steady-state region are higher for the 8 -pass condition with a grain size of $2 \mu \mathrm{m}$, while for the 2-pass material with a grain size of $3.5 \mu \mathrm{m}$ there is not much increase in indentation diagonal length. Hence, indentation creep occurs more readily in the material with a finer grain size.

It is generally accepted that the mechanical behavior of metallic materials at homologous temperatures higher than 0.3 can be fairly expressed by the power-law creep in a wide range strain rates. Thus, for steady-state creep, the relationship between the strain rate, $\dot{\varepsilon}$, and the tensile stress, $\sigma$, at a constant temperature can be expressed by:

$$
\dot{\varepsilon}=A \sigma^{n}=A \sigma^{1 / m}
$$

where $A$ is a constant, $n$ is the steady-state stress exponent, and $m$ is the SRS index defined as:

$$
m=\left[\frac{\partial \ln \sigma}{\partial \ln \dot{\varepsilon}}\right]_{\varepsilon}
$$

Assuming an analogy between strain and diagonal length from one side, and stress and hardness from the other side, the following relationship is obtained:
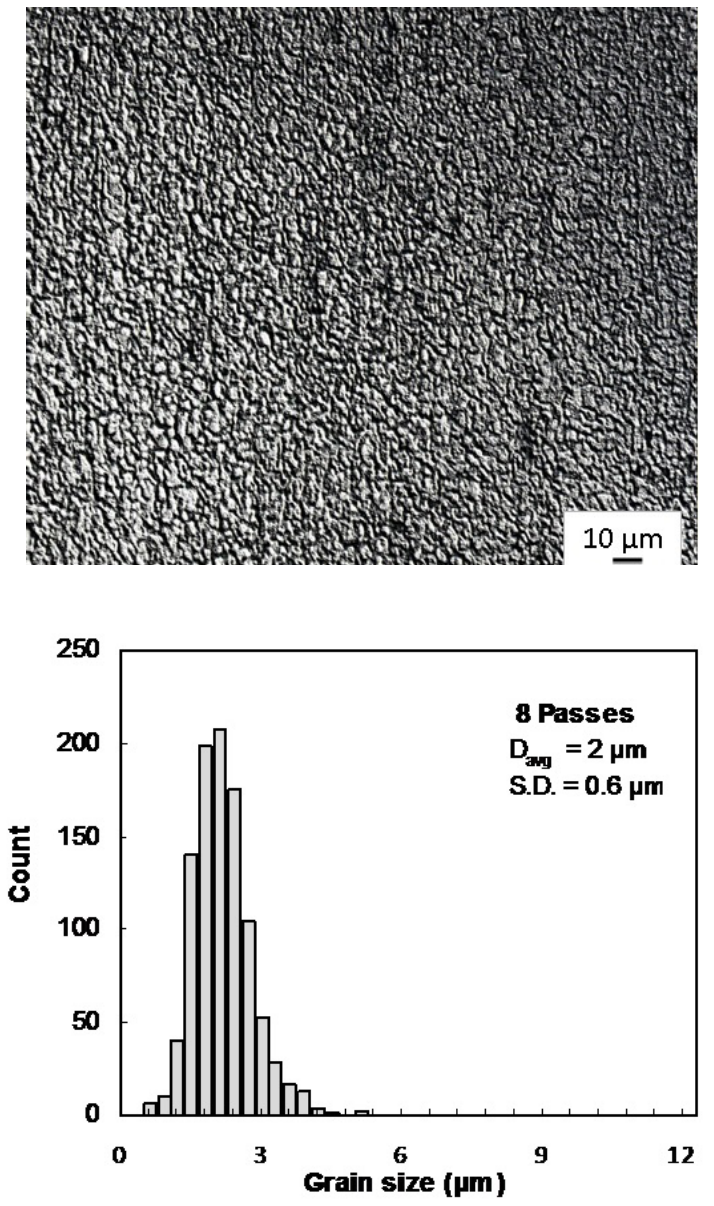

Fig. 3. (a) Optical micrograph and (b) grain size distribution of the material after 8 passes of MDF. 


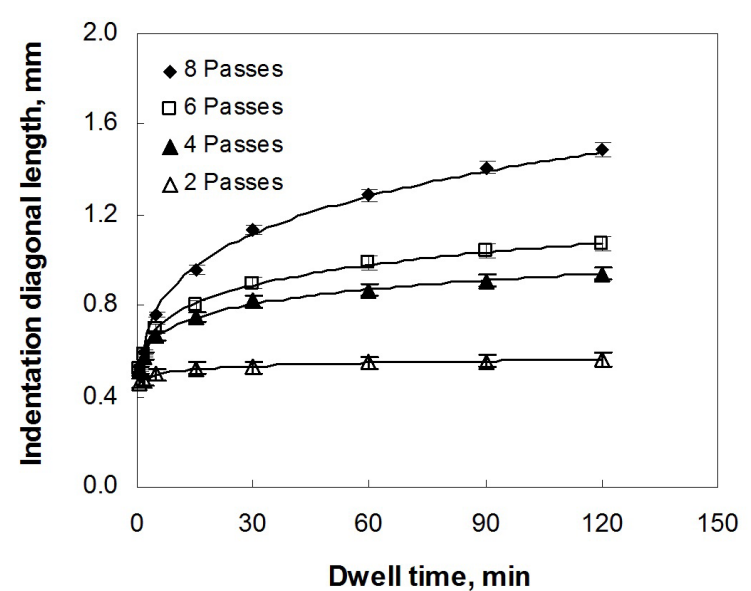

Fig. 4. Indentation creep curves for different conditions.

$$
m=\left[\frac{\partial \ln H_{v}}{\partial \ln \dot{d}}\right]_{d}
$$

where $H_{v}$ is the Vickers hardness number, $d$ is the indentation diagonal length, and $\dot{d}$ is the rate of variation in indentation length. This implies that if $H_{\mathrm{v}}$ is plotted against $\dot{d}$ on a double logarithmic scale, a straight line would be obtained, the slope of which is the stress exponent, $m$. This is shown in Fig. 5, where $m$-values in the range $0.08-0.5$ are obtained for the materials experiencing 2-8 MDF passes, respectively.

Sargent and Ashby [13] carried out hot hardness tests on a wide range of materials and proposed a dimensional analysis for indentation creep. According to their model, the displacement rate of an indenter has been derived as:

$$
\frac{d u}{d t}=\left[\frac{\dot{\varepsilon}_{0}}{C_{2}}(\sqrt{A})\right]\left[\left(\frac{C_{1}}{\sigma_{0}}\right)\left(\frac{P}{A}\right)\right]^{1 / m}
$$

where $A$ is the projected area of indentation, $C_{2}$ is a constant, $\dot{\varepsilon}_{0}$ is the rate at a reference stress $\sigma_{0}, m$ is the SRS index, and $P$ is the applied load. For a pyramid indenter the penetration is proportional to $\sqrt{A}$, i.e.,

$$
u=C_{3} \sqrt{A}
$$

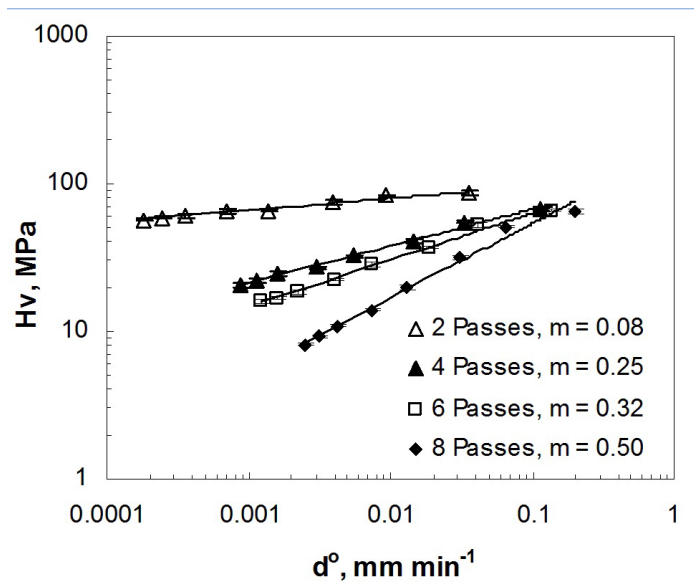

Fig. 5. Plots of $\ln \left(\mathrm{H}_{\mathrm{v}}\right)$ against $\ln \left(d^{\circ}\right)$ after different MDF passes to determine the SRS index, $m$.
Differentiating Eq. (5) with respect to time and substituting into Eq. (4) gives

$$
\frac{d A}{d t}=C_{4} \dot{\varepsilon}_{0} A\left(\frac{P}{A \sigma_{0}}\right)^{1 / m}
$$

where $C_{3}$ and $C_{4}$ are constants. When $P$ is held constant, Eq. (6) can be rewritten as

$$
\left(\frac{1}{H_{V}}\right)\left(\frac{d H_{V}}{d t}\right)=-C_{4} \dot{\varepsilon}_{0}\left(\frac{H_{V}}{\sigma_{0}}\right)^{1 / m}
$$

According to Eq. (7), a plot of $\ln \left(H_{\mathrm{v}}\right)$ versus $\ln [(-1 / H \mathrm{v})$ $(\mathrm{d} H \mathrm{v} / \mathrm{d} t)]$ at a constant temperature has a slope of $m$. The results obtained by this approach are illustrated in Fig. 6 for all material conditions. Similar to the previous method of analysis, lines with different single slopes of $m$ are obtained for each condition. The obtained $m$-values are in the range 0.08-0.48 for the materials after 2 to $8 \mathrm{MDF}$ passes.

Sargent and Ashby have also derived the following relationship between indentation hardness and dwell time:

$$
H_{V}(t)=\frac{\sigma_{0}}{\left(n C_{4} \dot{\varepsilon}_{0} t\right)^{m}}
$$

where $H_{\mathrm{v}}(t)$ is the time-dependent hardness. Hence, from Eq. (8), the slope of a plot of $\ln \left(H_{\mathrm{v}}\right)$ against $\ln (t)$ at a constant temperature is $-m$. The results obtained based on this approach are demonstrated in Fig. 7. This figure shows that the hardness of all tested conditions of the material can be represented as linear functions of time. Accordingly, $m$-values calculated from the slope of the fitted lines were found to be 0.08-0.48 for the materials after 2 to $8 \mathrm{MDF}$ passes.

One interesting point on the hardness results in Figs. 4 through 7 is that the $H v$ values are reduced with increasing numbers of MDF passes whereas grain sizes are reduced. This may seem to be against the Hall-Petch relationship, from which one may expect higher hardness values at smaller grain sizes. The softening behavior of the HPT-processed materials is recently reviewed by Kawasaki [14]. It has been stated that there is a unique softening behavior in metals and alloys after

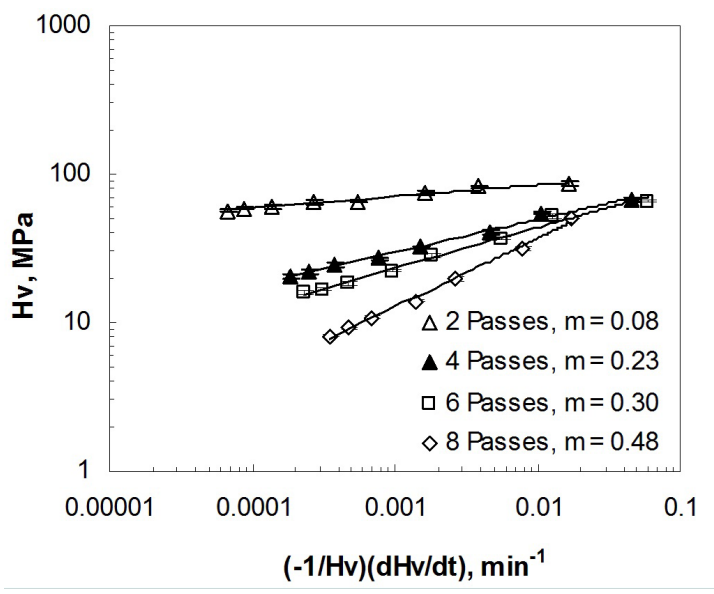

Fig. 6. The $\ln (H v)$ vs. $\ln [(-1 / H v)(d H v / d t)]$ curves with the slope of $m$. 


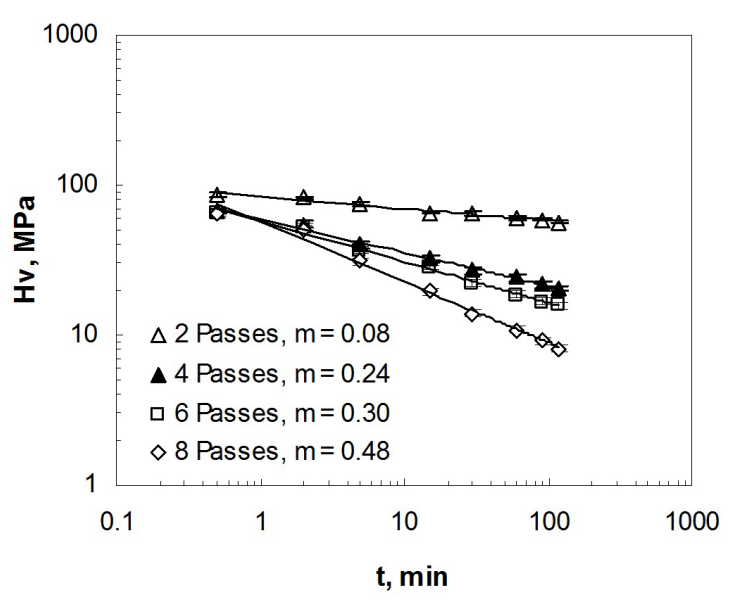

Fig. 7. Hardness-dwell time log-log plots giving straight lines with the slope of $-m$.

HPT when the homologous temperature of processing is very high. This has been reported to be the case in ultrafinegrained $\mathrm{Zn}-22 \% \mathrm{Al}$ eutectoid and ultrafine-grained $\mathrm{Pb}-62 \%$ Sn eutectic alloys after HPT at room temperature. Different microstructural reasons such as significant reduction in the distribution of the stable hexagonal close-packed $\mathrm{Zn}$ precipitates in $\mathrm{Zn}-\mathrm{Al}$ [15] and similar loss in precipitation in the $\mathrm{Pb}-\mathrm{Sn}$ alloy during deformation by HPT [16] have been put forward for the observed softening after severe plastic deformation of these materials. In a recent report, the plasticity and strain rate sensitivity of an ultrafine-grained $\mathrm{Zn}-22 \% \mathrm{Al}$ alloy after HPT was examined by nanoindentation which demonstrated the clear softening and increasing $m$-values with increasing number of HPT turns [17].

In all of the above studies, softening has been manifested by a detectable drop in either yield stress or hardness values measured after deformation. The nature of this softening behavior is different from that observed in the present study. Here, the short-term hardness values obtained at the dwell time of $0.5 \mathrm{~min}$ are very close for all conditions of the material, as shown in Fig. 4. On the other hand, the difference in the measured hardness values of the material after different MDF passes at longer dwell times is significantly high. This implies that creep resistance is strongly affected by the number of MDF passes, while the short-term hardness that is an indication of the yield stress is not much changed. In other words, smaller grain size has provided a higher density of grain boundaries, which can ease grain boundary sliding of the stressed material during dwell time, the effect which is not dominant in short-term hardness tests.

A summary of the SRS indices calculated via each of the above mentioned approaches are given in Table 1 for all tested conditions. As can be seen the $m$-values calculated by different approaches are in good agreement with each other, indicating the similarity of the derivation methods. It is also evident that the obtained $m$-values increase with increasing the number of MDF passes. The average $m$-values of 0.08 , $0.24,0.31$ and 0.49 are obtained for the material after 2, 4, 6 and 8 passes of MDF, respectively.

The observed difference in the indentation behavior, as indicated by different $\mathrm{m}$-values of the material after several MDF passes, can be attributed to their grain sizes and grain
Table 1. The SRS indices of the materials after different passes of MDF derived from different methods.

\begin{tabular}{ccccc}
\hline & \multicolumn{3}{c}{ SRS index, $m$} & \\
\cline { 2 - 4 } $\begin{array}{c}\text { Condi- } \\
\text { tion }\end{array}$ & $\begin{array}{c}\ln (H \mathrm{v}) \\
v s . \\
\ln \left(d^{\circ}\right)\end{array}$ & $\begin{array}{c}\ln (H \mathrm{v}) v s . \\
\ln [(-1 / H \mathrm{v}) \\
(\mathrm{d} H \mathrm{v} / \mathrm{d} t)]\end{array}$ & $\begin{array}{c}\ln (H \mathrm{v}) \\
\text { As. } \ln (t)\end{array}$ & $\begin{array}{c}\text { Average } \\
m \text {-value }\end{array}$ \\
\hline 2 Passes & 0.08 & 0.08 & 0.08 & 0.08 \\
4 Passes & 0.25 & 0.23 & 0.24 & 0.24 \\
6 Passes & 0.32 & 0.30 & 0.30 & 0.31 \\
8 Passes & 0.50 & 0.48 & 0.48 & 0.49 \\
\hline
\end{tabular}

types. By increasing the number of MDF passes the grain size decreases and SRS index increases. This behavior is in agreement with the Gifkins' core-mantle theory suggesting that for a constant width of mantle, an increasingly fine grain size results in a domination of the mantle behavior and thus, the SRS index begins to increase [18]. It is worth noting that although the unMDFed material possesses a relatively small grain size of $4.2 \mu \mathrm{m}$, its SRS index of less than 0.08 is not as high as those of the material after MDF. This is believed to be due to the presence of some coarse grains, which have resulted in the non-uniformity of the grain structure with a relatively high standard deviation of $1.9 \mu \mathrm{m}$ in the unMDFed condition. Moreover, the lack of high angle grain boundaries that are essential for the achievement of high SRS indices can be another possible reason for the observed behavior. On the contrary, it seems that processing by MDF not only refines the grain structure, but also increases the density of the high-angle grain boundaries. The high $\mathrm{m}$-values of 0.49 obtained after 8 passes of MDF are in accord with this argument. It is well accepted that at SRS index values close to 0.5 , superplastic deformation mechanisms such as grain boundary sliding become prominent [19]. SRS indices of about 0.45 to 0.5 have been reported in the indentation creep of a superplastic lead-tin eutectic alloy [8]. More recently, SRS indices of about 0.4 have been reported for the $S n-1 B i$ alloy processed by four passes of ECAP [11]. It is therefore concluded that after 8 passes of MDF, the present $\mathrm{Sn}-1 \mathrm{Bi}$ alloy can develop a fine-grained microstructure with superplastic indentation behavior caused by grain boundary sliding.

\section{Conclusions}

1. It is experimentally shown that an indentation creep test provides a convenient method for measuring strain rate sensitivity (SRS) and thereby assessing the ability of a material to undergo superplastic deformation.

2. The SRS indices calculated from different methods of analysis are in good agreement with each other. The average SRS values obtained from different approaches were found to be $0.08,0.24,0.31$ and 0.49 for the $2,4,6$ and 8 passes of MDF, respectively. This implies that with increasing numbers of MDF passes, the SRS indices increase and superplastic deformation is encouraged.

3. The highest $m$-value of 0.49 , obtained for the alloy after 8 MDF passes, together with a very fine-grained microstructure with an average grain size of $2 \mu \mathrm{m}$ are indicative of a grain boundary sliding mechanism at room temperature 


\section{References}

1. M. Noda, M. Hirohashi, K. Funami, Mater. Trans. 44, 2288 (2003).

2. J.Y. Xing, X. Yang, H. Miura, T. Sakai, Mater. Trans. 48, 1406 (2007).

3. A. Gennady, E. A. K. Salishchev, V. Sergey, S. Zherebtsov, S. L. Semiatin, Mater. Sci. Forum. 735, 253 (2012).

4. O. Sitdikov, T. Sakai, A. Goloborodko, H. Miura, R. Kaibyshev, Mater.Trans. 45, 2232 (2004).

5. O. Sitdikov, T. Sakai T, A. Goloborodko, H. Miura, Scr. Meter. 51, 175 (2004).

6. R. Mahmudi, R. Roumina, B. Raeisinia, Mater. Sci. Eng. A38, 215 (2004).

7. R. Mahmudi, A.R. Geranmayeh, S.R. Mahmoodi, A. Khalatbari, J. Mater. Sci.: Mater Electron. 18, 1071 (2007).

8. A. Juhasz, P. Tasnadi, I. Kovacs, J. Mater. Sci. Lett. 5, 35 (1986).
9. R. Mahmudi, A. Rezaee-Bazzaz, Mater. Letts. 59, 1705 (2005).

10. R. Mahmudi, A. Rezaee-Bazzaz, J. Mater. Sci. 42, 4051 (2007).

11. R. Mahmudi, H. Mhjoubi, P. Mehraram, Int. J. Modern Phys. B. 22, 2823 (2008).

12. R. Kapoor, A. Sarkar, R. Yogi, S. K. Shekhawat, I. Samajdar, J. K. Chakravartty, Mater. Sci. Eng. A 560, 404 (2013).

13. P. M. Sargent, M. F. Ashby, Mater. Sci. Tech. 8, 594 (1992). 14. M. Kawasaki, J. Mater. Sci. 49, 18 (2014).

15. M. Furukawa, Z. Horita, M. Nemoto, R.Z. Valiev, T. G. Langdon, J. Mater. Res. 11, 2128 (1996).

16. N. Zhang, M. Kawasaki, Y. Huang, T.G. Langdon, J. Mater. Sci. 48, 4582 (2013).

17. I. C. Choi, Y. J. Kim, B. Ahn, M. Kawasaki, T. G. Langdon, J. I. Jang, Scr. Mater. 75, 102 (2014).

18. R. C. Gifkins, Metall Trans 7A, 225 (1976).

19. T. G. Langdon, Mater. Sci. Eng. A 283, 266 (2000) . 